\title{
C.J.Liu ${ }^{1,2}, Z$.L.Zheng ${ }^{3}, X . Y . Y a n g^{4}, J . J . G u o^{5}$ \\ GEOMETRIC NONLINEAR VIBRATION ANALYSIS FOR PRETENSIONED RECTANGULAR ORTHOTROPIC MEMBRANE
}

\author{
${ }^{1}$ State Key Laboratory of Geohazard Prevention and Geoenvironment Protection, \\ Chengdu University of Technology, Chengdu 610059, China; \\ ${ }^{2}$ College of Environment and Civil Engineering, Chengdu University of Technology, \\ Chengdu 610059, China; \\ ${ }^{3}$ College of Civil Engineering, Chongqing University, \\ Chongqing 400044, China; \\ ${ }^{4}$ College of nuclear technology and automation Engineering, \\ Chengdu University of Technology Chengdu 610059, China; \\ ${ }^{5}$ Chongqing Water Resources and Electric Engineering College, Yongchuan, \\ Chongqing 402160, China(Corresponding author: Yang Xiao-yan, \\ email: yangxiaoyancd@126.com)
}

\begin{abstract}
The geometric nonlinear vibrations of pretensioned orthotropic membrane with four edges fixed, which is commonly applied in building membrane structure, are studied. The nonlinear partial differential governing equations are derived by von Kármán's large deflection theory and D'Alembert's principle. Because of the strong nonlinearity of governing equations, the homotopy perturbation method (HPM) to solve them is applied. The approximate analytical solution of the vibration frequency and displacement function is obtained. In the computational example, the frequency, vibration mode and displacement as well as the time curve of each feature point are analyzed. It is proved that HPM is an effective, simple and high-precision method to solve the geometric nonlinear vibration problem of membrane structures. These results provide some valuable computational basis for the vibration control and dynamic design of building and other analogous membrane structures.
\end{abstract}

Key words: nonlinear vibration, orthotropic, membrane, perturbation method.

\section{Introduction.}

The membrane structure is a thin flexible structure, so it is easy to engender vibration and relaxation deformation under the external load, thus results in engineering accident. Therefore, it is quite necessary to study the vibration characteristic of membrane structure to provide some computational basis for the design of membrane element and structure to ensure the safety and practicability of membrane element and structure.

There are number of reports about the linear and nonlinear vibration problem of membranes. Wang et al. [1] studied the vibration characteristics of the wrinkled square membrane structure subjected to the asymmetric tension and obtained some important conclusions for the structural design and optimization of membrane space structures. Jenkins and Korde [2] presented a experimental research on membrane vibration, and the results is valuable for the control-structure-interaction community. Li et al. [3] analyzed the wrinkling characteristics and dynamic mechanical behavior of membrane by eigenvalue method. The results indicated that the stress in wrinkled area is not uniform and vibration modes of wrinkled membrane are strongly correlated with the wrinkling configurations. The free vibration problems of composite rectangular membranes with oblique and bent interface were studied 
by using an analytical method by Kang and Lee $[4,5]$. The results showed that the natural frequencies and their associated modes obtained by them are very accurate compared with the results by the FEM or exact solutions. The vibration problems of rectangular membranes placed in a vertical plane were solved and the exact solutions of the vibration frequencies were obtained by Wang [6]. Gonalves and Soares [7, 8] presented the mathematical modeling for the nonlinear vibration analysis of a prestretched hyperelastic circular and annular membrane under finite deformations. Zheng et al. [9] studied the dynamic response of rectangular orthotropic membranes under impact loading by analytical and numerical method. Shin et al.[10]investigated the geometric nonlinear dynamic characteristics of the out-ofplane vibration of an axially moving membrane by using Hamilton's principle and Galerkin's method. The results showed that the translating speed, boundary conditions and aspect ratio of the membrane have effects on the natural frequencies, mode shapes and stability for the out-of-plane vibration of the moving membrane. Zhang and Shan [11] studied initial equilibrium shape and free vibration poperties pre-tensioned membrane structures by applying relaxation method. Example analysis demonstrated that the method is a simple, practical and accurate geometric nonlinear method to study the tensioned cladding-network with big span. Li et al. [12] presented NBA-UM (Nonlinear Buckling Analysis-Update Matrix) method to analyze the vibration behaviors of the wrinkled membrane. The results reveal that the wrinkles have great effects on the free vibration characteristics of wrinkled membrane. Pan and Gu [13] studied the effects of membrane's pre-strain, size, elastic ratio, density, relative amplitude and dead load of square tensioned membrane to the structure's nonlinearity and deduced the free oscillating system's equivalent fundamental frequency. Reutskiy [14] adopted a new numerical method to study nonlinear vibration of arbitrarily shaped membranes. The method is based on mathematical modeling of physical response of a system that was excited over a range of frequencies. Formosa [15] presented a work devoted to the study of the operation of a miniaturized membrane Stirling engine. The nonlinearities of large amplitude vibration of Stirling engine were concerned, and the stability analysis to predict the starting of the engine and the instability problem that leads to the steady-state behavior were displayed. Zheng and Liu et al. [16, 17] studied the geometric nonlinear vibration problem of orthotropic membrane structures by power series expansion method and L - P (Lindstedt - Poincaré ) method. But the results are only suitable for the weak nonlinear situation. In many cases, the amplitude of the membrane is much larger than its thickness in vibration process, so the vibration is a strong geometric nonlinear vibration. Therefore, it is necessary to pursue an effective method for solving the strong nonlinear vibration of membrane structures.

The homotopy perturbation method (HPM) introduced by He [18 - 21] is an effective method to solve strong nonlinear problems. It is widely applied to mathematics, mechanics, economics, and biology and so on. For instance, the nonlinear oscillator with discontinuities was studied by He [22] by using HPM. Cveticanin [23] studied pure nonlinear differential equation by HPM. Yildirim [24] applied HPM to solve the Fokker-Planck equation. EISayed et al. [25] solved partial differential equations of fractional order in finite domains by HPM. Golbabai and Javidi [26] proposed HPM to solve $\mathrm{n}^{\text {th }}$-order integro-differential equations. Ozturk and Coskun [27] applied HPM to analysis the free vibration of beam on elastic foundation. Saffari et al. [28] applied HPM to elasto-plastic analysis of steel plane frames. Ghotbi et al.[29] solved ratio-dependent predator-prey system with constant effort harvesting using HPM. Reck et al. [30] solved the Helmholtz equation in conformal mapped ARROW structures using HPM. Andrianov et al. [31] used HPM to analyze the natural in-plane vibration of rectangular plates. Domairry and Aziz [32] presented approximate analysis of MHD squeeze flow between two parallel disks with suction or injection by HPM. In addition to these researches, there are many other applications of HPM [33, 34].

In this paper, we studied the strong geometrical nonlinear vibration of pretensioned orthotropic membrane structure with four edges simply supported or fixed by using HPM, and obtained the approximate analytical solution of the vibration frequency and displacement function. The computational example showed HPM is an effective and very simple method for solving the strong geometrical nonlinear vibration of membrane structures and the results have a very high precision. 


\section{Governing equations and boundary conditions.}

The orthotropic membrane is mainly applied in building structure, and it is generally simplified and considered as a rectangular structure. In Figs.1 and 2, each member of the building membrane structure roof can be considered as a rectangular orthotropic membrane structure with four edges simply supported or fixed.

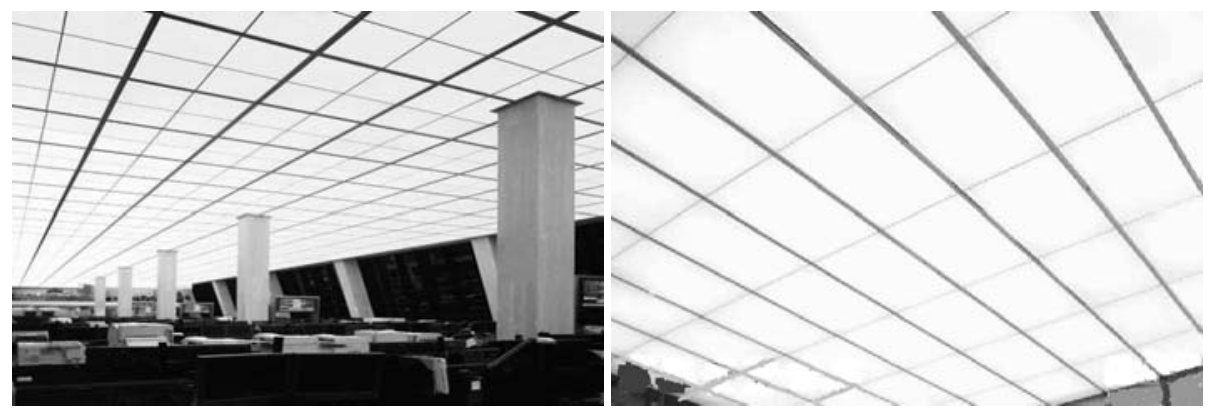

Fig. 1. The membrane roof of one office building

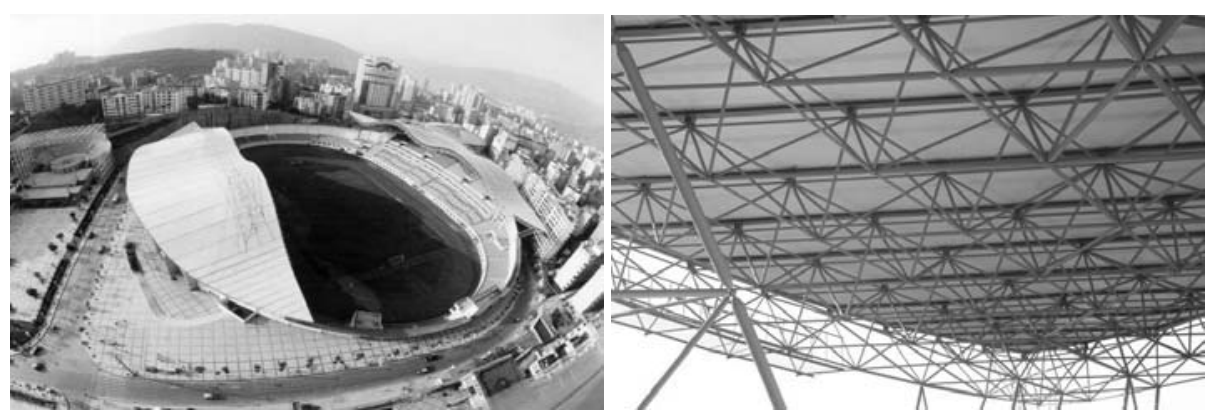

Fig. 2. The membrane roof of one stadium

The orthotropic membrane's two orthogonal directions are the two principal fiber directions, and the material characteristics of the two principal fiber directions are different. The simplified theoretical model for the orthotropic membrane is shown in Fig. 2, 3. The two principal fiber directions are $x$ and $y$, respectively. $a$ and $b$ denote the length of $x$ and $y$ directions, respectively; $N_{0 x}$ and $N_{0 y}$ denote the initial tension in $x$ and $y$ directions, respectively.

According to the Von Kármán's membrane large deflection theory and D'Alembert's principle $[16,17]$, the vibration partial differential equation and consistency equation of orthotropic membrane are:

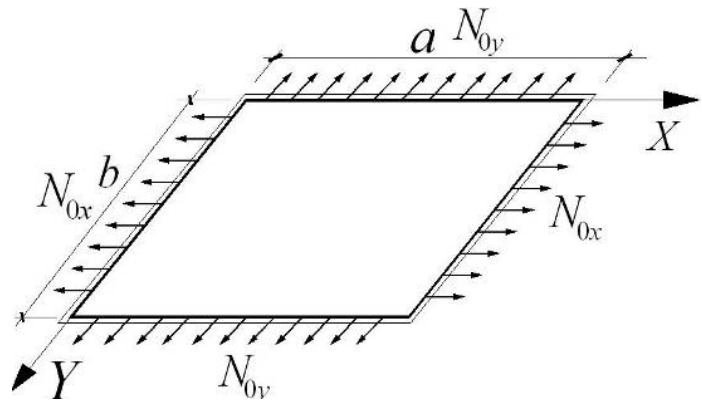

Fig. 3. Rectangle membrane with four edges simply supported 


$$
\begin{gathered}
\rho \frac{\partial^{2} w}{\partial t^{2}}-\left(N_{x}+N_{0 x}\right) \frac{\partial^{2} w}{\partial x^{2}}-\left(N_{y}+N_{0 y}\right) \frac{\partial^{2} w}{\partial y^{2}}-2\left(N_{x y}+N_{0 x y}\right) \frac{\partial^{2} w}{\partial x \partial y}=0 \\
\frac{1}{E_{1} h} \frac{\partial^{2} N_{x}}{\partial y^{2}}-\frac{\mu_{2}}{E_{2} h} \frac{\partial^{2} N_{y}}{\partial y^{2}}-\frac{\mu_{1}}{E_{1} h} \frac{\partial^{2} N_{x}}{\partial x^{2}}+\frac{1}{E_{2} h} \frac{\partial^{2} N_{y}}{\partial x^{2}}-\frac{1}{G h} \frac{\partial^{2} N_{x y}}{\partial x \partial y}=\left(\frac{\partial^{2} w}{\partial x \partial y}\right)^{2}-\frac{\partial^{2} w}{\partial x^{2}} \frac{\partial^{2} w}{\partial y^{2}},
\end{gathered}
$$

where $\rho$ denotes aerial density of membrane; $N_{x}$ and $N_{y}$ denote additional tension in $x$ and $y$ direction, respectively; $N_{0 x}$ and $N_{0 y}$ denote initial tension in $x$ and $y$ direction, respectively; $N_{x y}$ denotes additional shear force; $N_{0 x y}$ denote initial shear force; $w$ denotes deflection $w(x, y, t) ; h$ denotes membrane's thickness; $E_{1}$ and $E_{2}$ denote Young's modulus in $x$ and $y$ direction, respectively; $G$ denotes shearing modulus; $\mu_{1}$ and $\mu_{2}$ denote Poisson's ratio in $x$ and $y$ direction, respectively.

Introduce the stress function, we have

and set

$$
N_{x}=h \frac{\partial^{2} \varphi}{\partial y^{2}} ; \quad N_{y}=h \frac{\partial^{2} \varphi}{\partial x^{2}} ; \quad N_{x y}=-h \frac{\partial^{2} \varphi}{\partial x \partial y}
$$

$$
N_{0 x}=h \cdot \sigma_{0 x} ; \quad N_{0 y}=h \cdot \sigma_{0 y} ; \quad N_{0 x y}=-h \cdot \sigma_{0 x y} .
$$

Then governing equations (1) can be simplified as follows:

$$
\begin{aligned}
& \frac{\rho}{h} \frac{\partial^{2} w}{\partial t^{2}}-\left(\sigma_{0 x}+\frac{\partial^{2} \varphi}{\partial y^{2}}\right) \frac{\partial^{2} w}{\partial x^{2}}-\left(\sigma_{0 y}+\frac{\partial^{2} \varphi}{\partial x^{2}}\right) \frac{\partial^{2} w}{\partial y^{2}}+\left(\sigma_{0 x y}+\frac{\partial^{2} \varphi}{\partial x \partial y}\right) \frac{\partial^{2} w}{\partial x \partial y}=0 \\
& \frac{1}{E_{1}} \frac{\partial^{4} \varphi}{\partial y^{4}}+\frac{1}{E_{2}} \frac{\partial^{4} \varphi}{\partial x^{4}}-\frac{\mu_{2}}{E_{2}} \frac{\partial^{4} \varphi}{\partial x^{2} \partial y^{2}}-\frac{\mu_{1}}{E_{1}} \frac{\partial^{4} \varphi}{\partial x^{2} \partial y^{2}}+\frac{1}{G} \frac{\partial^{4} \varphi}{\partial x^{2} \partial y^{2}}=\left(\frac{\partial^{2} w}{\partial x \partial y}\right)^{2}-\frac{\partial^{2} w}{\partial x^{2}} \frac{\partial^{2} w}{\partial y^{2}},
\end{aligned}
$$

where $\varphi$ denotes stress function $\varphi(x, y, t), \sigma_{0 x}$ and $\sigma_{0 y}$ denote initial tensile stress in $x$ and $y$ direction, respectively. $\sigma_{0 x y}$ denotes initial shear stress.

The corresponding boundary conditions are as follows:

$$
\begin{aligned}
& \left\{\begin{array} { l } 
{ w ( 0 , y , t ) = 0 , \frac { \partial ^ { 2 } w } { \partial x ^ { 2 } } ( 0 , y , t ) = 0 ; } \\
{ w ( a , y , t ) = 0 , \frac { \partial ^ { 2 } w } { \partial x ^ { 2 } } ( a , y , t ) = 0 ; }
\end{array} \left\{\begin{array}{l}
w(x, 0, t)=0, \frac{\partial^{2} w}{\partial y^{2}}(x, 0, t)=0 ; \\
w(x, b, t)=0, \frac{\partial^{2} w}{\partial y^{2}}(x, b, t)=0 ;
\end{array}\right.\right. \\
& \left\{\begin{array} { l } 
{ \frac { \partial ^ { 2 } \varphi } { \partial x ^ { 2 } } ( 0 , y , t ) = 0 ; } \\
{ \frac { \partial ^ { 2 } \varphi } { \partial x ^ { 2 } } ( a , y , t ) = 0 ; }
\end{array} \quad \left\{\begin{array} { l } 
{ \frac { \partial ^ { 2 } \varphi } { \partial y ^ { 2 } } ( x , 0 , t ) = 0 ; } \\
{ \frac { \partial ^ { 2 } \varphi } { \partial y ^ { 2 } } ( x , b , t ) = 0 ; }
\end{array} \quad \left\{\begin{array} { l } 
{ \frac { \partial ^ { 2 } \varphi } { \partial x \partial y } ( x , 0 , t ) = 0 ; } \\
{ \frac { \partial ^ { 2 } \varphi } { \partial x \partial y } ( x , b , t ) = 0 ; }
\end{array} \quad \left\{\begin{array}{l}
\frac{\partial^{2} \varphi}{\partial x \partial y}(0, y, t)=0 ; \\
\frac{\partial^{2} \varphi}{\partial x \partial y}(a, y, t)=0 .
\end{array}\right.\right.\right.\right.
\end{aligned}
$$

3. Simplification of Governing Equations.

Functions that satisfy the boundary conditions (4) and (5) can be written as follows:

$$
\begin{aligned}
& w(x, y, t)=\sum_{m=1}^{\infty} \sum_{n=1}^{\infty} u_{m n}(t) \cdot W_{m n}(x, y) ; \\
& \varphi(x, y, t)=\sum_{m=1}^{\infty} \sum_{n=1}^{\infty} U_{m n}(t) \cdot \phi_{m n}(x, y),
\end{aligned}
$$


where $W(x, y)$ is the mode shape function; and $\phi_{m n}(x, y), u_{m n}(t)$ and $U_{m n}(t)$ are the unknown functions. Substituting Eqs. (6) and (7) into Eq. (3) yields

$$
\begin{gathered}
\sum_{m=1}^{\infty} \sum_{n=1}^{\infty}\left(\frac{1}{E_{1}} \frac{\partial^{4} \phi_{m n}(x, y)}{\partial y^{4}}+\frac{1}{E_{2}} \frac{\partial^{4} \phi_{m n}(x, y)}{\partial x^{4}}+\left(\frac{1}{G}-\frac{\mu_{1}}{E_{1}}-\frac{\mu_{2}}{E_{2}}\right) \frac{\partial^{4} \phi_{m n}(x, y)}{\partial x^{2} \partial y^{2}}\right) \cdot U_{m n}(t)= \\
=\sum_{m=1}^{\infty} \sum_{n=1}^{\infty}\left(\left(\frac{\partial^{2} W_{m n}(x, y)}{\partial x \partial y}\right)^{2}-\frac{\partial^{2} W_{m n}(x, y)}{\partial x^{2}} \frac{\partial^{2} W_{m n}(x, y)}{\partial y^{2}}\right) \cdot u_{m n}^{2}(t) .
\end{gathered}
$$

To equate the two ends of Eq. (8), it must be $U_{m n}(t)=u_{m n}^{2}(t)$. Then Eq. (7) can be rewritten as follows:

$$
\varphi(x, y, t)=\sum_{m=1}^{\infty} \sum_{n=1}^{\infty} u_{m n}^{2}(t) \cdot \phi_{m n}(x, y) .
$$

In order to simplify the computing process, we can take one item of Eqs. (6) and (9) to compute, namely

$$
\begin{gathered}
w(x, y, t)=u_{m n}(t) \cdot W_{m n}(x, y) ; \\
\varphi(x, y, t)=u_{m n}^{2}(t) \cdot \phi_{m n}(x, y),
\end{gathered}
$$

where

$$
u_{m n}(t)=u(t)=u, W_{m n}(x, y)=W(x, y)=W, \varphi(x, y, t)=\varphi, \phi_{m n}(x, y)=\phi(x, y)=\phi .
$$

According to the vibration theory of membrane, the mode shape function that satisfy the boundary condition (4) is

$$
W_{m n}(x, y)=W(x, y)=W=\sin \frac{m \pi x}{a} \sin \frac{n \pi y}{b},
$$

where $m$ and $n$ are integers and denote the sine half-wave number in $x$ and $y$, respectively.

Substituting Eqs. (10) and (11) into Eq. (3) yields

$$
\frac{1}{E_{1}} \frac{\partial^{4} \phi}{\partial y^{4}}+\frac{1}{E_{2}} \frac{\partial^{4} \phi}{\partial x^{4}}+\left(\frac{1}{G}-\frac{\mu_{1}}{E_{1}}-\frac{\mu_{2}}{E_{2}}\right) \frac{\partial^{4} \phi}{\partial x^{2} \partial y^{2}}=\left(\frac{\partial^{2} W}{\partial x \partial y}\right)^{2}-\frac{\partial^{2} W}{\partial x^{2}} \frac{\partial^{2} W}{\partial y^{2}} .
$$

Substituting Eq. (12) into Eq. (13) yields

$$
\frac{1}{E_{1}} \frac{\partial^{4} \phi}{\partial y^{4}}+\frac{1}{E_{2}} \frac{\partial^{4} \phi}{\partial x^{4}}+\left(\frac{1}{G}-\frac{\mu_{1}}{E_{1}}-\frac{\mu_{2}}{E_{2}}\right) \frac{\partial^{4} \phi}{\partial x^{2} \partial y^{2}}=\frac{m^{2} n^{2} \pi^{4}}{2 a^{2} b^{2}}\left(\cos \frac{2 m \pi x}{a}+\cos \frac{2 n \pi y}{b}\right) .
$$

From analysis of the solution structure of Eq. (14) and the boundary conditions, we can assume the solution of (14) is

$$
\phi(x, y)=\alpha \cdot \cos \frac{2 m \pi x}{a}+\beta \cdot \cos \frac{2 n \pi y}{b}+\gamma_{1} x^{3}+\gamma_{2} y^{3}+\gamma_{3} x^{2} y+\gamma_{4} x y^{2}+\gamma_{5} x^{2}+\gamma_{6} y^{2}+\gamma_{7} x y .
$$

Substituting Eq. (15) into Eq. (14) yields

$$
\frac{16 m^{4} \pi^{4} \alpha}{a^{4} E_{2}} \cos \frac{2 m \pi x}{a}+\frac{16 n^{4} \pi^{4} \beta}{b^{4} E_{1}} \cos \frac{2 n \pi y}{a}=\frac{m^{2} n^{2} \pi^{4}}{2 a^{2} b^{2}}\left(\cos \frac{2 m \pi x}{a}+\cos \frac{2 n \pi y}{b}\right) .
$$

From Eq.(16), we obtain $\alpha=\frac{E_{2} n^{2} a^{2}}{32 m^{2} b^{2}} ; \beta=\frac{E_{1} m^{2} b^{2}}{32 n^{2} a^{2}}$. 
Substituting Eq. (15) into boundary condition (5) yields

$$
\left\{\begin{array} { l } 
{ \frac { \partial ^ { 2 } \phi } { \partial x ^ { 2 } } ( 0 , y , t ) = 2 \gamma _ { 3 } y + 2 \gamma _ { 5 } - \alpha \frac { 4 m ^ { 2 } \pi ^ { 2 } } { a ^ { 2 } } = 0 ; } \\
{ \frac { \partial ^ { 2 } \phi } { \partial x ^ { 2 } } ( a , y , t ) = 6 \gamma _ { 1 } a + 2 \gamma _ { 3 } y + 2 \gamma _ { 5 } - \alpha \frac { 4 m ^ { 2 } \pi ^ { 2 } } { a ^ { 2 } } = 0 ; } \\
{ \frac { \partial ^ { 2 } \phi } { \partial y ^ { 2 } } ( x , 0 , t ) = 2 \gamma _ { 4 } x + 2 \gamma _ { 6 } - \beta \frac { 4 n ^ { 2 } \pi ^ { 2 } } { b ^ { 2 } } = 0 ; } \\
{ \frac { \partial ^ { 2 } \phi } { \partial y ^ { 2 } } ( x , b , t ) = 6 \gamma _ { 2 } b + 2 \gamma _ { 4 } x + 2 \gamma _ { 6 } - \beta \frac { 4 n ^ { 2 } \pi ^ { 2 } } { b ^ { 2 } } = 0 ; } \\
{ \frac { \partial ^ { 2 } \phi } { \partial x \partial y } = \gamma _ { 7 } = 0 . }
\end{array} \quad \Rightarrow \left\{\begin{array}{l}
\gamma_{1}=\gamma_{2}=\gamma_{3}=\gamma_{4}=\gamma_{7}=0 ; \\
\gamma_{5}=\frac{\pi^{2} E_{2} n^{2}}{16 b^{2}} \\
\gamma_{6}=\frac{\pi^{2} E_{1} m^{2}}{16 a^{2}}
\end{array}\right.\right.
$$

Substituting $\alpha, \beta, \gamma_{1}, \gamma_{2}, \gamma_{3}, \gamma_{4}, \gamma_{5}, \gamma_{6}, \gamma_{7}$ into Eq. (15), and then substituting Eq. (15) into Eq. (11) yields

$$
\varphi(x, y, t)=\left(\frac{E_{2} n^{2} a^{2}}{32 m^{2} b^{2}} \cos \frac{2 m \pi x}{a}+\frac{E_{1} m^{2} b^{2}}{32 n^{2} a^{2}} \cos \frac{2 n \pi y}{b}+\frac{\pi^{2} E_{2} n^{2}}{16 b^{2}} x^{2}+\frac{\pi^{2} E_{1} m^{2}}{16 a^{2}} y^{2}\right) u^{2}(t) \text {. }
$$

Substituting Eqs. (10), (11) and (17) into Eq. (2) and according to the Galerkin method, we have

$$
\begin{gathered}
\iint_{S}\left[\frac{\rho}{h} \frac{\partial^{2} w}{\partial t^{2}}-\left(\sigma_{0 x}+\frac{\partial^{2} \varphi}{\partial y^{2}}\right) \frac{\partial^{2} w}{\partial x^{2}}-\left(\sigma_{0 y}+\frac{\partial^{2} \varphi}{\partial x^{2}}\right) \frac{\partial^{2} w}{\partial y^{2}}+\left(\sigma_{0 x y}+\frac{\partial^{2} \varphi}{\partial x \partial y}\right) \frac{\partial^{2} w}{\partial x \partial y}\right] W d s= \\
=\iint_{S}\left[\frac{\rho}{h} W \frac{\partial^{2} u(t)}{\partial t^{2}}-\left(\sigma_{0 x} \cdot \frac{\partial^{2} W}{\partial x^{2}}+\sigma_{0 y} \cdot \frac{\partial^{2} W}{\partial y^{2}}-\sigma_{0 x y} \cdot \frac{\partial^{2} W}{\partial x \partial y}\right) u(t)-\right. \\
\left.-\left(\frac{\partial^{2} W}{\partial x^{2}} \frac{\partial^{2} \phi}{\partial y^{2}}+\frac{\partial^{2} W}{\partial y^{2}} \frac{\partial^{2} \phi}{\partial x^{2}}-2 \frac{\partial^{2} W}{\partial x \partial y} \frac{\partial^{2} \phi}{\partial x \partial y}\right) u^{3}(t)\right] W d s=0 .
\end{gathered}
$$

Obviously, Eq. (18) is a nonlinear differential equation with respect to $u(t)$ :

$$
\xi_{1} \cdot \frac{d^{2} u(t)}{d t^{2}}+\xi_{2} \cdot u(t)+\xi_{3} \cdot u^{3}(t)=0,
$$

where

$$
\begin{gathered}
\xi_{1}=\iint_{S} \frac{\rho}{h} W^{2} d s=\iint_{S} \frac{\rho}{h} \sin ^{2} \frac{m \pi x}{a} \sin ^{2} \frac{n \pi y}{b} d s=\frac{\rho a b}{4 h} \\
\xi_{2}=-\iint_{S}\left(\sigma_{0 x} \cdot \frac{\partial^{2} W}{\partial x^{2}}+\sigma_{0 y} \cdot \frac{\partial^{2} W}{\partial y^{2}}-\sigma_{0 x y} \cdot \frac{\partial^{2} W}{\partial x \partial y}\right) W d s=\frac{\pi^{2} a b}{4}\left(\frac{m^{2}}{a^{2}} \sigma_{0 x}+\frac{n^{2}}{b^{2}} \sigma_{0 y}\right) ; \\
\xi_{3}=-\iint_{S}\left(\frac{\partial^{2} W}{\partial x^{2}} \frac{\partial^{2} \phi}{\partial y^{2}}+\frac{\partial^{2} W}{\partial y^{2}} \frac{\partial^{2} \phi}{\partial x^{2}}-2 \frac{\partial^{2} W}{\partial x \partial y} \frac{\partial^{2} \phi}{\partial x \partial y}\right) W d s=\frac{3 a b \pi^{4}}{64}\left(\frac{E_{1} m^{4}}{a^{4}}+\frac{E_{2} n^{4}}{b^{4}}\right) .
\end{gathered}
$$

Substituting the value of $\xi_{1}, \xi_{2}$ and $\xi_{3}$ into (19) and, yields:

$$
\frac{d^{2} u(t)}{d t^{2}}+\frac{h \pi^{2}}{\rho}\left(\frac{m^{2}}{a^{2}} \sigma_{0 x}+\frac{n^{2}}{b^{2}} \sigma_{0 y}\right) u(t)+\frac{3 h \pi^{4}}{16 \rho}\left(\frac{E_{1} m^{4}}{a^{4}}+\frac{E_{2} n^{4}}{b^{4}}\right) u^{3}(t)=0 .
$$


By setting $\lambda=\frac{h \pi^{2}}{\rho}\left(\frac{m^{2}}{a^{2}} \sigma_{0 x}+\frac{n^{2}}{b^{2}} \sigma_{0 y}\right)$ and $\varepsilon=\frac{3 h \pi^{4}}{16 \rho}\left(\frac{E_{1} m^{4}}{a^{4}}+\frac{E_{2} n^{4}}{b^{4}}\right)$, then we have

$$
\frac{d^{2} u(t)}{d t^{2}}+\lambda \cdot u(t)+\varepsilon \cdot u^{3}(t)=0 .
$$

In many cases, $\varepsilon$ is not a small perimeter in Eq. (20), namely Eq. (20) is a strong nonlinear vibration equation.

\section{Solution of Governing Equations.}

4.1. Basic idea of homotopy perturbation method. We use the homotopy perturbation method (HPM) to solve Eq. (20) in this paper. The HPM is a new, effective and concise method for solving the strong nonlinear problems. It does not depend on the small perimeter and has high accuracy. In order to illustrate the basic idea of this method, we consider the following nonlinear differential equation

$$
A(u)-f(\boldsymbol{r})=0, \quad r \in \Omega
$$

with boundary conditions

$$
B(u, \partial u / \partial n)=0, \quad r \in \Gamma,
$$

where $A$ is a general differential operator, $B$ is a boundary operator, $f(\boldsymbol{r})$ is a known analytic function, $\Gamma$ is the boundary of the domain $\Omega$.

The operator $A$ can, generally speaking, be divided into two parts $L$ and $N$, where $L$ is linear, while $N$ is nonlinear, Eq. (21), therefore, can be rewritten as follows

$$
L(u)+N(u)-f(\boldsymbol{r})=0 .
$$

By the homotopy technique, we construct a homotopy $v(r, p): \Omega \times[0,1] \rightarrow \mathbb{R}$, which satisfies

$$
\mathrm{H}(v, p)=(1-p)\left[L(v)-L\left(u_{0}\right)\right]+p[A(u)-f(r)]=0, p \in[0,1], r \in \Omega,
$$

or

$$
\mathrm{H}(v, p)=L(v)-L\left(u_{0}\right)+p L\left(u_{0}\right)+p[N(v)-f(\boldsymbol{r})]=0,
$$

where $p \in[0,1]$ is an embedding parameter, $u_{0}$ is an initial approximation of Eq. (21), which satisfies the boundary conditions. Obviously, from Eq. (24) or (25) we have

$$
\begin{aligned}
& \mathrm{H}(v, 0)=L(v)-L\left(u_{0}\right)=0 ; \\
& \mathrm{H}(v, 1)=A(v)-f(\boldsymbol{r})=0 .
\end{aligned}
$$

The changing process of $p$ from zero to unity is just that of $v(\boldsymbol{r}, p)$ from $u_{0}(\boldsymbol{r})$ to $u(\boldsymbol{r})$. In topology, this is called deformation, and $L(v)-L\left(u_{0}\right), A(v)-f(\boldsymbol{r})$ are called homotopic.

Because $0<p \leq 1$, we use the imbedding parameter $p$ as a "small parameter", and assume that the solution of Eq. (24) or (25) can be written as a power series in $p$ :

$$
v=v_{0}+p v_{1}+p^{2} v_{2}+\cdots
$$

Setting $p=1$ result in the approximate solution of Eq. (21):

$$
u=\lim _{p \rightarrow 1} v=v_{0}+v_{1}+v_{2}+\cdots .
$$

The coupling of the perturbation method and the homotopy method is called the homotopy perturbation method, which has eliminated limitations of the traditional perturbation methods. In the other hand, the proposed technique can take full advantage of the traditional perturbation techniques [18-22]. 
4.2. Homotopy perturbation solution for governing equations. Eq. (20) is a Duffing equation; it is rewritten with its initial condition:

$$
\frac{d^{2} u}{d t^{2}}+\lambda \cdot u+\varepsilon \cdot u^{3}=0, u(0)=a_{0}, u^{\prime}(0)=0 .
$$

We construct a homotopy which satisfies

$$
L(v)-L\left(u_{0}\right)+p L\left(u_{0}\right)+p \varepsilon v^{3}=0,
$$

where $L(u)=d^{2} u / d t^{2}+\lambda \cdot u$.

One may now try to obtain a solution of Eq. (31) in the form

$$
v(t)=v_{0}(t)+p \cdot v_{1}(t)+p^{2} \cdot v_{2}(t)+\cdots,
$$

where the $v_{i}(t), i=0,1,2 \cdots$ are functions yet to be determined. The substitution of Eq. (32) into Eq. (31) yields

$$
\begin{aligned}
& L\left(v_{0}\right)-L\left(u_{0}\right)=0 ; \quad v_{0}(0)=a_{0} ; v_{0}^{\prime}(0)=0 ; \\
& L\left(v_{1}\right)+L\left(u_{0}\right)+\varepsilon v_{0}^{3}=0 ; \quad v_{1}(0)=v_{1}^{\prime}(0)=0 .
\end{aligned}
$$

We set $v_{0}(t)=u_{0}(t)=a_{0} \cos \sqrt{\lambda} \alpha t$ with an unknown constant $\alpha$ as the initial approximation of Eq. (31). Therefore from Eq. (34), we have

$$
\frac{d v_{1}}{d t}+\lambda v_{1}+a_{0}\left(\lambda-\lambda \alpha^{2}+\frac{3}{4} \varepsilon a_{0}^{2}\right) \cos \sqrt{\lambda} \alpha t+\frac{1}{4} \varepsilon a_{0}^{3} \cos 3 \sqrt{\lambda} \alpha t=0 .
$$

Eq. (35) is a linear differential equation, and it can be solved easily. The solution of Eq. (35) is

$$
\begin{gathered}
v_{1}=\left(\lambda-\lambda \alpha^{2}+\frac{3}{4} \varepsilon a_{0}^{2}\right) \frac{a_{0}}{\lambda\left(\alpha^{2}-1\right)}(\cos \sqrt{\lambda} \alpha t-\cos \sqrt{\lambda} t)+ \\
+\frac{\varepsilon a_{0}^{3}}{4 \lambda\left(9 \alpha^{2}-1\right)}(\cos 3 \sqrt{\lambda} \alpha t-\cos \sqrt{\lambda} t) .
\end{gathered}
$$

In order to eliminate the secular term which may occur in the next iteration, we set the coefficient of " $\cos \sqrt{\lambda} t$ " zero:

$$
-\left(\lambda-\lambda \alpha^{2}+\frac{3}{4} \varepsilon a_{0}^{2}\right) \frac{a_{0}}{\lambda\left(\alpha^{2}-1\right)}-\frac{\varepsilon a_{0}^{3}}{4 \lambda\left(9 \alpha^{2}-1\right)}=0 .
$$

In Eq. (37), $\lambda \neq 0$, so we have

$$
\alpha=\sqrt{\frac{10 \lambda+7 \varepsilon a_{0}^{2}+\sqrt{64 \lambda^{2}+104 \lambda \varepsilon a_{0}^{2}+49 \varepsilon^{2} a_{0}^{4}}}{18 \lambda}} .
$$

Eq. (36), therefore, can be re-written as follows

$$
v_{1}=\left(\lambda-\lambda \alpha^{2}+\frac{3}{4} \varepsilon a_{0}^{2}\right) \frac{a_{0}}{\lambda\left(\alpha^{2}-1\right)} \cos \sqrt{\lambda} \alpha t+\frac{\varepsilon a_{0}^{3}}{4 \lambda\left(9 \alpha^{2}-1\right)} \cos 3 \sqrt{\lambda} \alpha t .
$$

In most cases, the first-order approximation is sufficient, and then we have

$$
u_{1}(t)=v_{0}(t)+v_{1}(t)=\frac{3 \varepsilon a_{0}^{3}}{4 \lambda\left(\alpha^{2}-1\right)} \cos \sqrt{\lambda} \alpha t+\frac{\varepsilon a_{0}^{3}}{4 \lambda\left(9 \alpha^{2}-1\right)} \cos 3 \sqrt{\lambda} \alpha t .
$$


The frequency of the solution can be expressed as follows

$$
\omega=\sqrt{\lambda} \alpha=\sqrt{\frac{10 \lambda+7 \varepsilon a_{0}^{2}+\sqrt{64 \lambda^{2}+104 \lambda \varepsilon a_{0}^{2}+49 \varepsilon^{2} a_{0}^{4}}}{18}},
$$

while the exact frequency is ${ }^{[16]}$

$$
\omega_{e x}=\frac{\sqrt{\lambda+\frac{\varepsilon}{2} a_{0}{ }^{2}}}{\sum_{p=0}^{\infty}(-1)^{p}\left(\frac{(2 p-1) ! !}{(2 p) ! !}\right)^{2}\left(\frac{\varepsilon a_{0}^{2}}{2 \lambda+\varepsilon a_{0}^{2}}\right)^{p}},
$$

where $p=0,1,2,3 \cdots$, and the frequency obtained by the $\mathrm{L}-\mathrm{P}$ perturbation method is [17]

$$
\omega_{\text {pert }}=\sqrt{\lambda}+\frac{3 \varepsilon a_{0}^{2}}{\sqrt{\lambda} 8} .
$$

Substituting Eqs.(3.7) and (4.20) into Eq.(3.1), we can obtain the displacement function of nonlinear free vibration of rectangular orthotropic membrane in large amplitude

$$
w(x, y, t)=\sum_{m=1}^{\infty} \sum_{n=1}^{\infty} \sin \frac{m \pi x}{a} \sin \frac{n \pi y}{b}\left(\frac{3 \varepsilon a_{0}^{3}}{4 \lambda\left(\alpha^{2}-1\right)} \cos \sqrt{\lambda} \alpha t+\frac{\varepsilon a_{0}^{3}}{4 \lambda\left(9 \alpha^{2}-1\right)} \cos 3 \sqrt{\lambda} \alpha t\right) .
$$

It is important to note that the coefficient $a_{0}$ is the single-order amplitude of membrane, $a_{0}$ is determined by the initial displacement of membrane. Assume the initial displacement of membrane is

$$
w(x, y, 0)=w_{0}(x, y) .
$$

According to the orthogonality of vibration mode, we have

$$
a_{0}=\frac{4}{a b} \int_{0}^{a} \int_{0}^{b} w_{0}(x, y) \sin \frac{m \pi x}{a} \sin \frac{n \pi y}{b} d x d y .
$$

Consequently, only in some simple and special case can we obtain the coefficient $a_{0}$, namely obtain the complete solution of membrane vibration. Assumming $w_{0}(x, y)=w_{0}$, and substituting it into Eq. (46), we have

$$
a_{0}=\left\{\begin{array}{cc}
\frac{16 w_{0}}{m n \pi^{2}} & (m, n=1,3,5 \cdots) \\
0 & (m, n=2,4,6 \cdots)
\end{array}\right.
$$

Form Eq. (48), we can see that $a_{0}$ decreases with the increase of vibration orders.

\section{Computational Examples and discussions.}

Take the membrane material commonly applied in project as an example. The Young's modulus in $x$ and $y$ are $E_{1}=1,4 \times 10^{6} \mathrm{KN} / \mathrm{m}^{2}$ and $E_{2}=0,9 \times 10^{6} \mathrm{KN} / \mathrm{m}^{2}$, respectively; the aerial density of membranes is $\rho=1,7 \mathrm{~kg} / \mathrm{m}^{2}$; the membrane's thickness is $h=1,0 \mathrm{~mm}, a=1 \mathrm{~m}$, $b=1 \mathrm{~m}, \sigma_{0 x}=\sigma_{0 y}=5,0 \times 10^{3} \mathrm{KN} / \mathrm{m}^{2}$.

5.1. Computation of frequency. According to the initial displacement $w_{0}$, we can figure out $a_{0}$ by Eq. (47). Then substitute $a_{0}$ into Eqs. (41), (42) and (43) to figure out the freqency of the first three orders. The results are shown in Table 1, and plot them in Figs. 4-6. 
Table 1: Frequency values ( $\mathrm{rad} / \mathrm{s})$ under different initial displacement

\begin{tabular}{|c|c|c|c|c|c|c|c|c|c|c|c|c|}
\hline \multirow{2}{*}{ 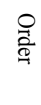 } & \multirow{2}{*}{ 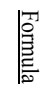 } & \multicolumn{11}{|c|}{ initial displacement $w_{0}(\mathrm{~m})$} \\
\hline & & 0,10 & 0,09 & 0,08 & 0,07 & 0,06 & 0,05 & 0,04 & 0,03 & 0,02 & 0,01 & $w_{0} \rightarrow 0$ \\
\hline \multirow{3}{*}{1} & (41) & 749,32 & 682,31 & 616,22 & 551,38 & 488,31 & 427,80 & 371,13 & 320,38 & 278,82 & 250,88 & 240,95 \\
\hline & (42) & 725,63 & 661,75 & 598,82 & 537,18 & 477,30 & 419,93 & 366,21 & 317,97 & 278,09 & 250,82 & 240,95 \\
\hline & (43) & 1251,66 & 1059,62 & 887,80 & 736,20 & 604,80 & 493,63 & 402,66 & 331,91 & 281,38 & 251,06 & 240,95 \\
\hline \multirow{3}{*}{2} & (41) & 1447,47 & 1323,23 & 1201,25 & 1082,34 & 967,63 & 858,84 & 758,58 & 670,71 & 600,64 & 554,80 & 538,78 \\
\hline & (42) & 1405,22 & 1286,99 & 1171,08 & 1058,21 & 949,45 & 846,33 & 751,16 & 667,32 & 599,71 & 554,73 & 538,78 \\
\hline & (43) & 2161,18 & 1852,93 & 1577,12 & 1333,76 & 1122,84 & 944,38 & 798,36 & 684,80 & 603,68 & 603,68 & 538,78 \\
\hline \multirow{3}{*}{3} & (41) & 1752,38 & 1594,08 & 1437,77 & 1284,18 & 1134,44 & 990,34 & 854,77 & 732,60 & 631,70 & 563,27 & 538,78 \\
\hline & (42) & 1695,88 & 1544,89 & 1395,98 & 1249,87 & 1107,64 & 970,97 & 842,48 & 726,44 & 629,80 & 563,10 & 538,78 \\
\hline & (43) & 3034,62 & 2560,41 & 2136,12 & 1761,74 & 1437,28 & 1162,74 & 938,11 & 763,40 & 638,61 & 563,74 & 538,78 \\
\hline
\end{tabular}

The comparison and analysis of Table 1 and Figs. $4-6$ are as follows.

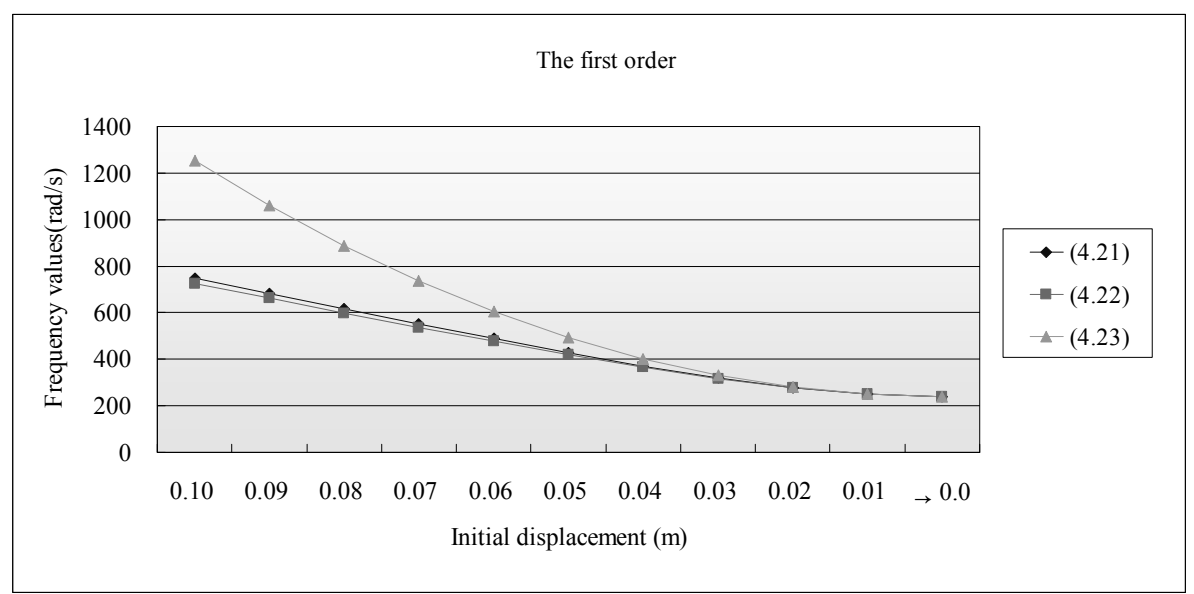

Fig. 4. Frequency values of the first order under different initial displacement

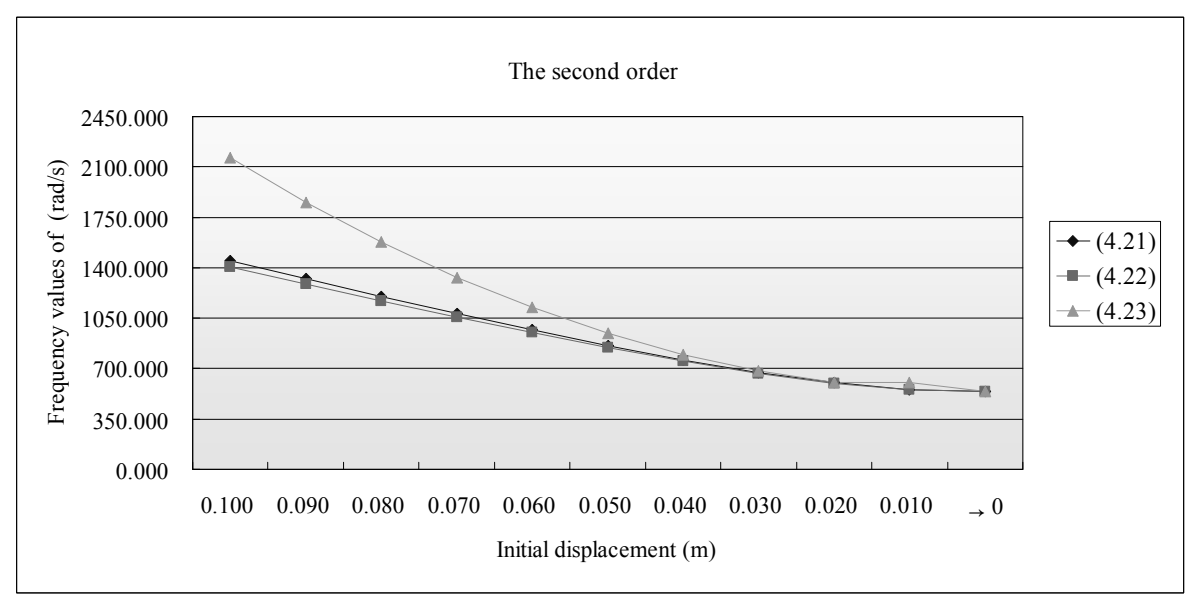

Fig. 5. Frequency values of the second order under different initial displacement 


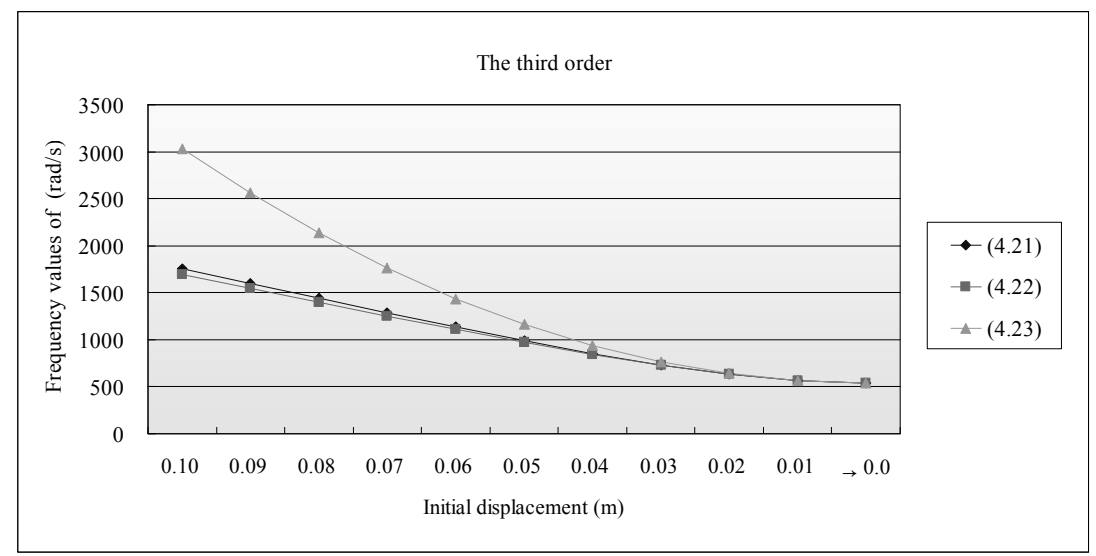

Fig. 6. Frequency values of the second order under different initial displacement

1. All of the frequency values calculated according to Eqs. (41), (42) and (43) enlarge with the increase of initial displacement. This is due to the fact that the inner force, lateral rigidity and elastic restoring force will increase with the increase of initial displacement of membrane, and then the membrane will vibrate more quickly. This reflects the geometric nonlinearity characteristic of the vibration of membrane in large amplitude. Meanwhile, the frequency values under the same initial displacement enlarge with the increase of orders. When the initial displacement approaches zero, namely $w_{0} \rightarrow 0$, the frequency values calculated according to Eqs. (41), (42) and (43) are the same and equal to the small amplitude vibration frequency values.

2. The frequency values calculated according to Eq. (41) are slightly larger than the corresponding ones calculated according to Eq. (42). The relative differences between them become larger and larger with the increase of initial displacement, and the maximal relative difference is 3,33\% in Table 1 and Figs. $4-6$.

3. The frequency values calculated according to Eq. (43) are larger than the corresponding ones calculated according to Eq. (42). The relative differences between them increase dramatically with the increase of initial displacement, and the maximal relative difference is 78,94\% in Table 1 and Figs. $4-6$.

4. When the initial displacement is small and order is low, the frequency values computed by Eq. (41), (42) and (43) are very close. When $w_{0} \leq 0,04$, the maximum relative difference between them is $11,35 \%$. Therefore, we can infer that while $w_{0} / a \leq 0,04$, using Eqs. (41) and (43) to compute the frequency of first three orders can satisfy the engineering precision and is very simple and convenient.

5. Obviously, the precision of Eq. (41) is higher than Eq. (43). Eq. (43) is only suitable for the situation of weak nonlinear vibration of membrane, namely Eq. (43) is valid only for small parameters. Eq. (41) is not only suitable for the situation of weak nonlinear vibration of membrane, but also suitable for the situation of strong nonlinear vibration of membrane, namely Eq. (43) is valid not only for small parameters, but also for large parameters.

5.2. Further discussions of frequency. In Table 1, the maximum initial displacement is $w_{0}=0,1 \mathrm{~m}$ and the maximal relative difference between the two corresponding frequency values of Eqs. (41) and (42) is 3,33\%. But if $w_{0}$ is larger, even $w_{0} \rightarrow \infty$ (or $a_{0} \rightarrow \infty, \varepsilon a_{0}^{2} \rightarrow \infty$ ) how about the precision of (41)? Hence we construct a limit as follows:

$$
\begin{aligned}
& \lim _{\varepsilon a_{0}^{2} \rightarrow \infty}=\frac{\omega_{e x}}{\omega}= \\
& =\frac{\sqrt{\lambda+\frac{\varepsilon}{2} a_{0}^{2}}}{\sqrt{\frac{10 \lambda+7 \varepsilon a_{0}^{2}+\sqrt{64 \lambda^{2}+104 \lambda \varepsilon a_{0}^{2}+49 \varepsilon^{2} a_{0}^{4}}}{18}} \cdot \sum_{p=0}^{\infty}(-1)^{p}\left(\frac{(2 p-1) ! !}{(2 p) ! !}\right)^{2}\left(\frac{\varepsilon a_{0}^{2}}{2 \lambda+\varepsilon a_{0}^{2}}\right)^{p}}=0,96065 .
\end{aligned}
$$


Therefore, for any value of $w_{0}$ (or $a_{0}, \varepsilon a_{0}^{2}$ ), it can be easily proved that the maximal relative error is less than 3,935\%.

5.3. Analysis of vibration modes. Substituting the material and geometric parameters in computational example and the frequency values calculated by Eq. (41) (while $w_{0}=0,05 \mathrm{~m}$ ) into Eq. (44), we obtain the displacement function of the vibration of the first three orders.

1. The first order vibration mode

$$
w(x, y, t)=(0,0789866 \cos 427,8 t+0,00207038 \cos 1283,4 t) \sin \pi x \sin \pi y .
$$

2. The second order vibration mode

$$
w(x, y, t)=(0,026399 \cos 858,84 t+0,000620067 \cos 2576,52 t) \sin \pi x \sin 3 \pi y .
$$

3. The third order vibration mode

$$
w(x, y, t)=(0,0263092 \cos 858,84 t+0,000709343 \cos 2971,02 t) \sin 3 \pi x \sin \pi y .
$$

According to these displacement functions, we can draw the vibration mode figures of the first three orders while $t=0,02 s$ in Figs. 7 to 9. Superposing the vibration mode of the first four orders, we can obtain the superposed vibration mode figure in Fig. 10.

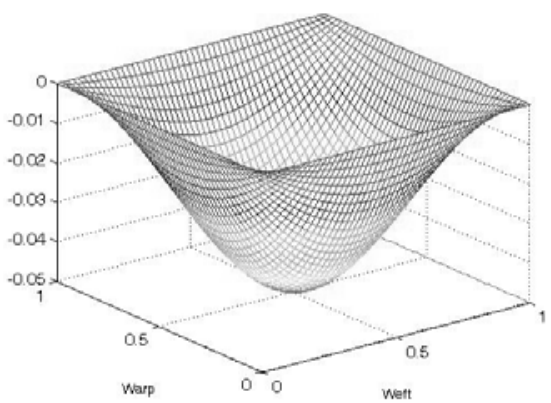

Fig. 7. The first order vibration mode

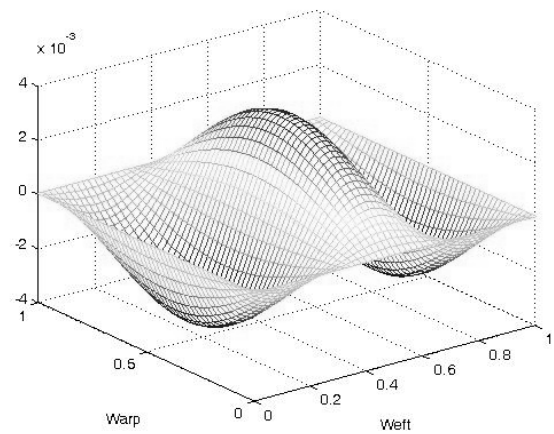

Fig. 9. The third order vibration mode

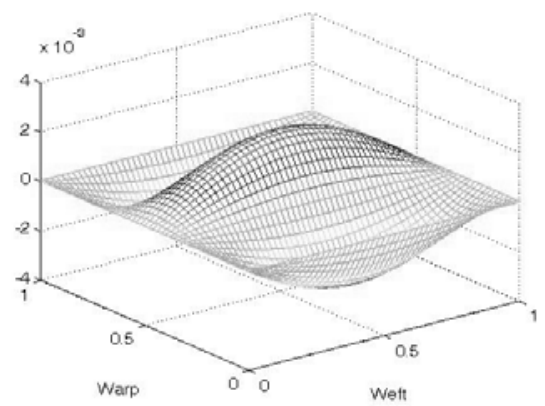

Fig. 8. The second order vibration mode

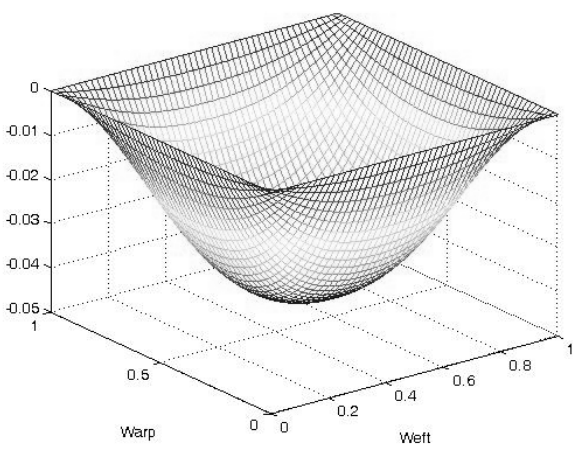

Fig. 10. The superposed vibration mode of the first three orders

From the result of the vibration mode analysis, we can conclude that the amplitude decrease with orders, namely the contribution of high orders for total mode decrease gradually. In addition, using the displacement function (44) can compute the vibration mode of each order and obtain the total superposed vibration mode conveniently, and the total mode is axisymmetric.

5.4. Analysis of displacement time histories of feature points. Substituting the material and geometric parameters in computational example and the frequency values calculated 


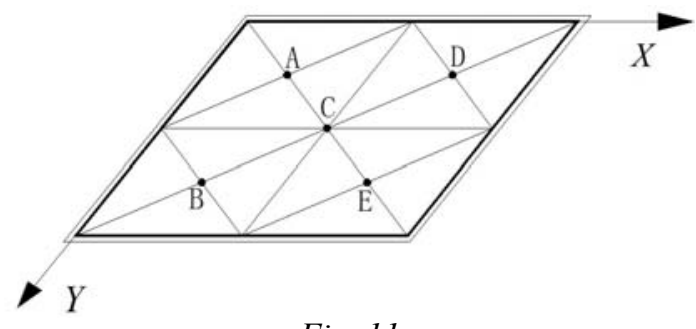

Fig. 11

according to Eq. (41) (while $w_{0}=0,05 \mathrm{~m}$ ) into Eq. (44), we can compute the displacement time histories of the feature points on membrane surface and draw the displacement and time curves. The feature points are $A(x=0,25 \mathrm{~m}, y=0,25 \mathrm{~m}), B(x=0,25 \mathrm{~m}, y=0,75 \mathrm{~m}), C$ $(x=0,5 \mathrm{~m}, y=0,5 \mathrm{~m}), D(x=0,75 \mathrm{~m}, y=0,25 \mathrm{~m})$ and $E(x=0,75 \mathrm{~m}, y=0,75 \mathrm{~m})$, and they are shown in Fig. 11.

The first three single-order displacement time histories are shown in Figs. $12-26$ and the superposed displacement time histories of the first three orders are shown in Figs. 27 - 31.

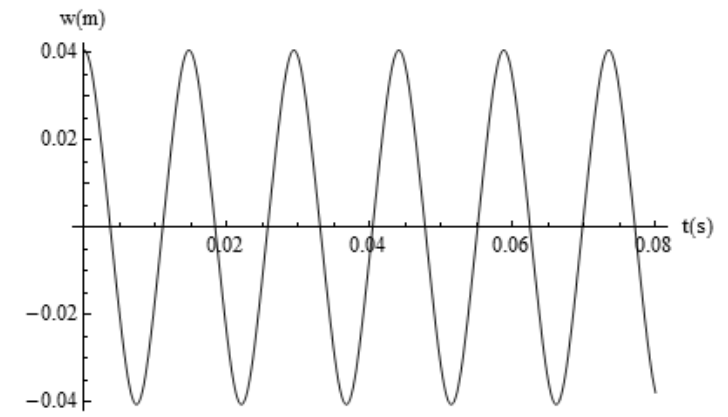

Fig. 12. Displacement and time curve of $A$ point (1st order)

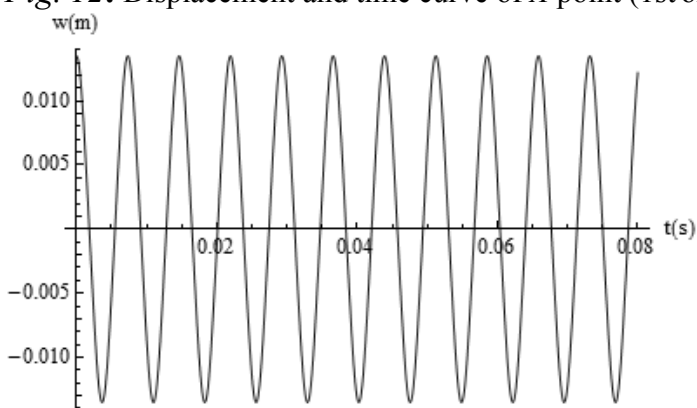

Fig. 13. Displacement and time curve of $A$ point (2nd order)

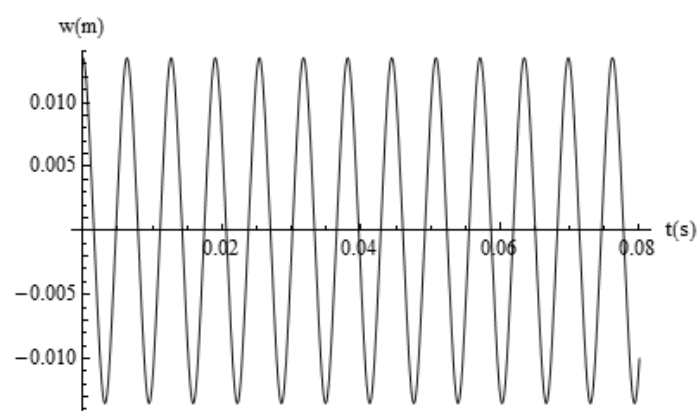

Fig. 14. Displacement and time curve of $A$ point (3rd order) 


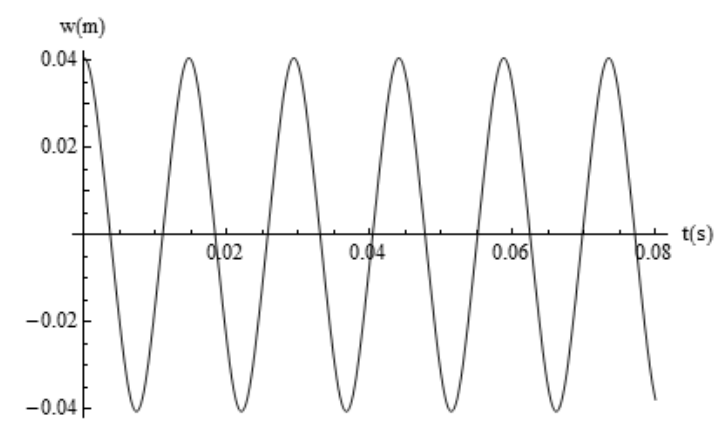

Fig. 15. Displacement and time curve of $B$ point (1st order)

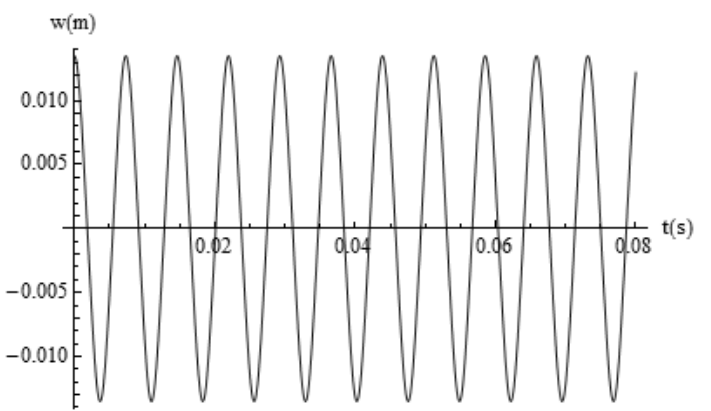

Fig. 16. Displacement and time curve of $B$ point (2nd order)

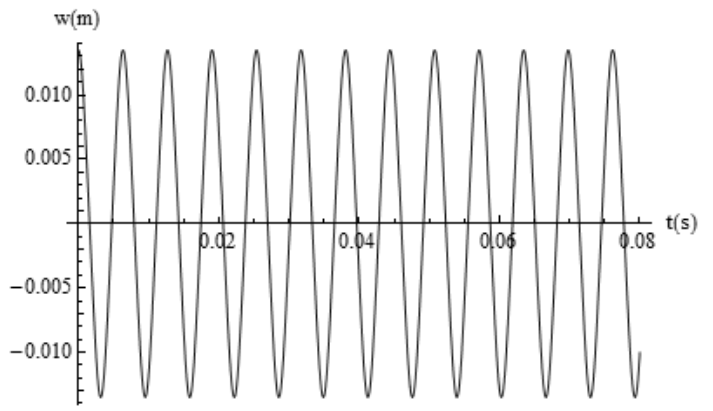

Fig. 17. Displacement and time curve of $B$ point (3rd order)

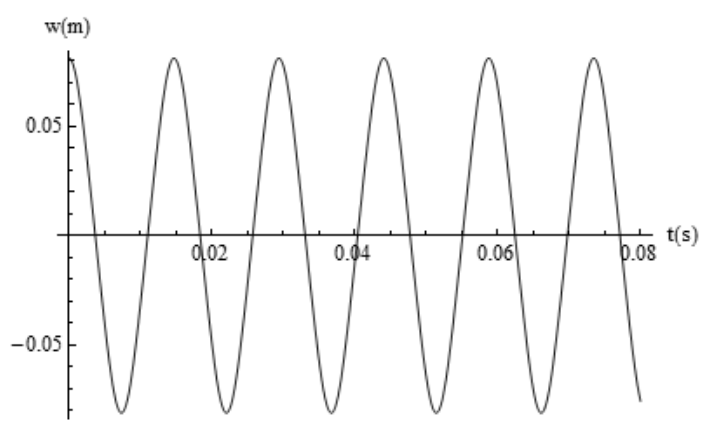

Fig. 18. Displacement and time curve of $C$ point (1st order) 


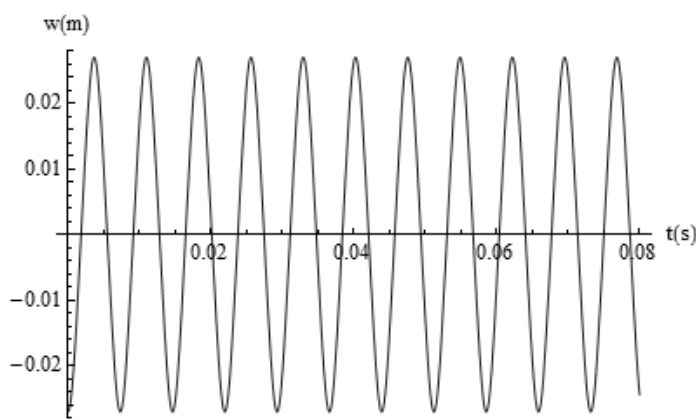

Fig. 19. Displacement and time curve of $C$ point (2nd order)

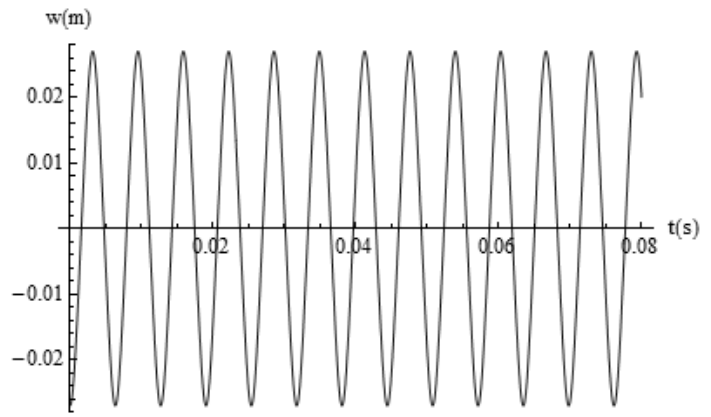

Fig. 20. Displacement and time curve of $C$ point (3rd order)

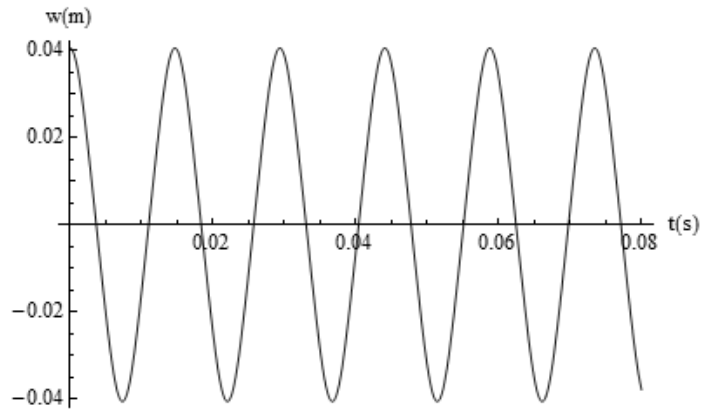

Fig. 21. Displacement and time curve of $D$ point (1st order)

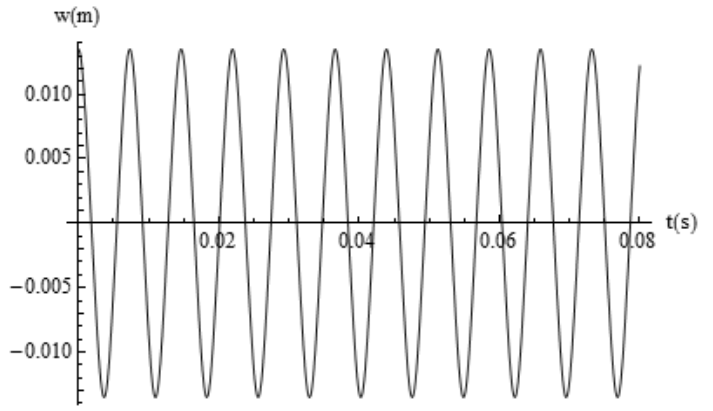

Fig. 22. Displacement and time curve of $D$ point (2nd order) 


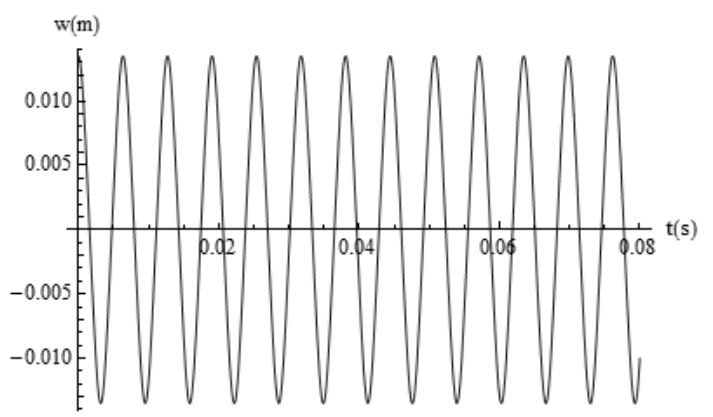

Fig. 23.Displacement and time curve of $D$ point (3rd order)

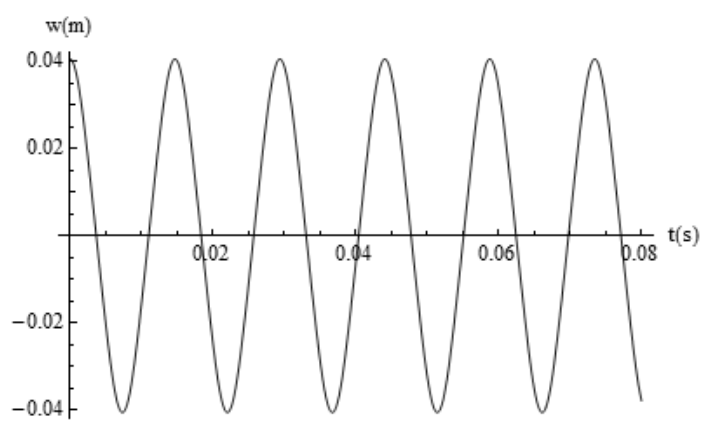

Fig. 24. Displacement and time curve of $E$ point (1st order)

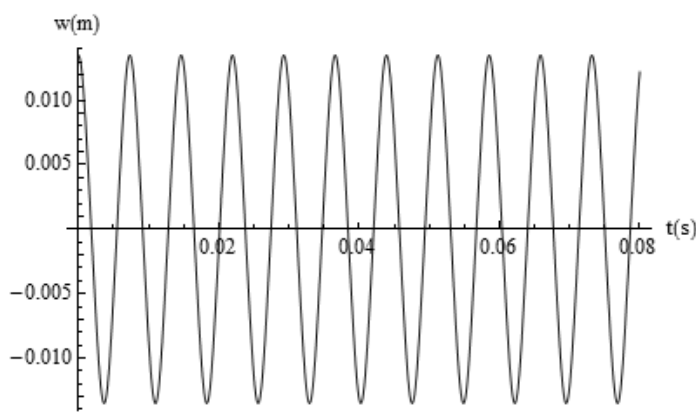

Fig. 25. Displacement and time curve of $D$ point (2nd order)

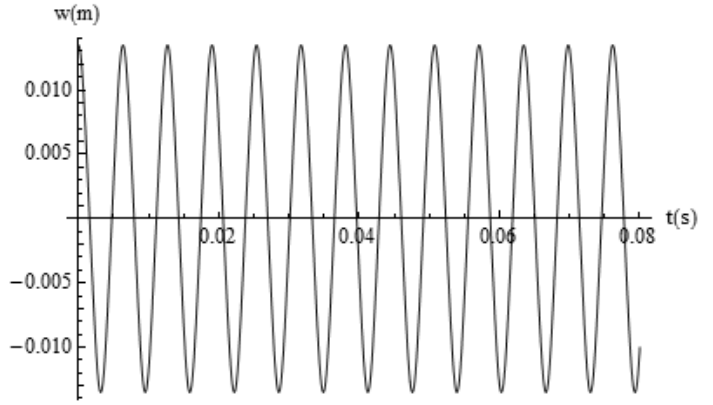

Fig. 26. Displacement and time curve of $D$ point (3rd order) 


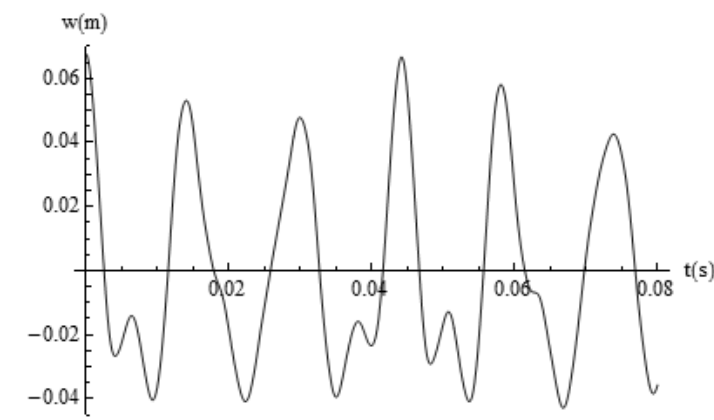

Fig. 27. Superposed displacement and time curve of $A$ point

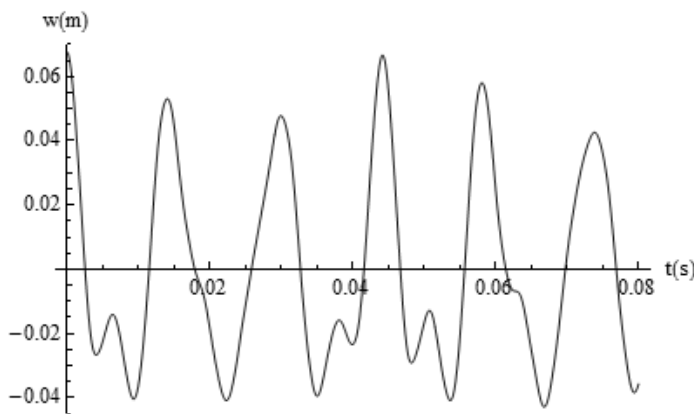

Fig. 28. Superposed displacement and time curve of $B$ point

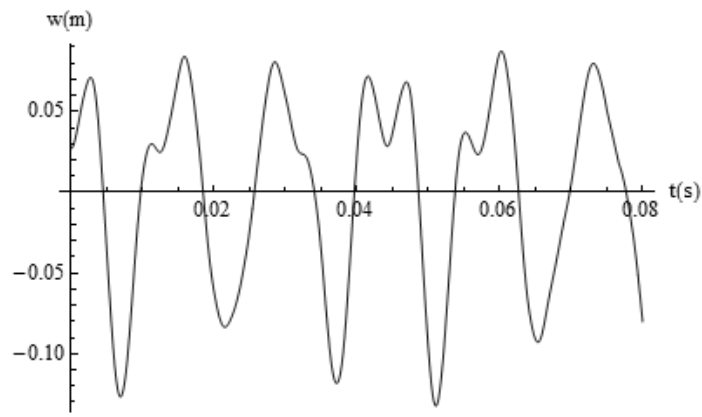

Fig. 29. Superposed displacement and time curve of $C$ point

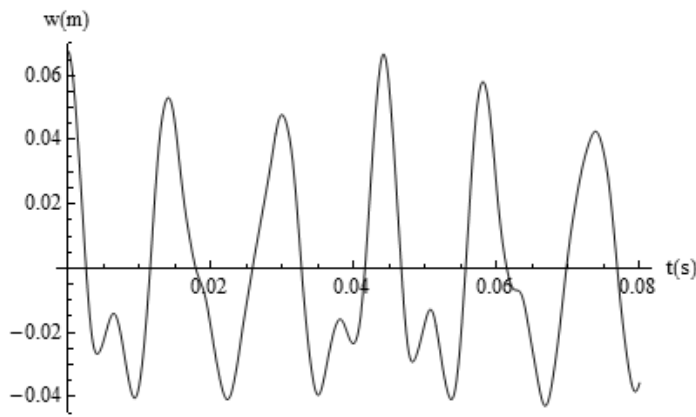

Fig. 30. Superposed displacement and time curve of $D$ point 


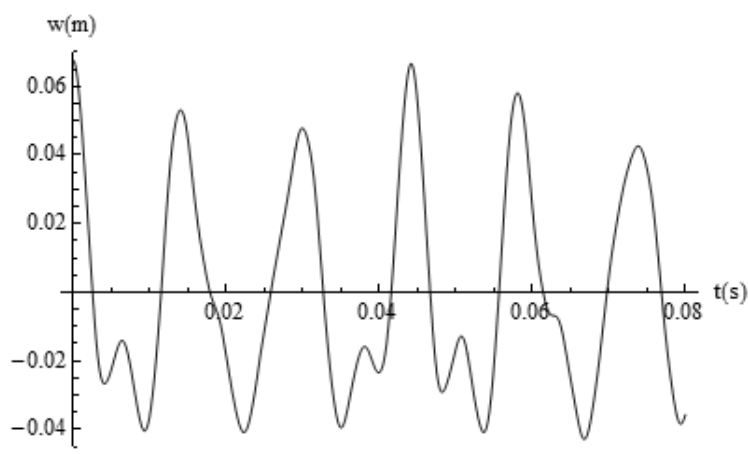

Fig. 31. Superposed displacement and time curve of $E$ point

From the analysis of displacement time histories, we can obtain the following conclusion.

We can obtain the single-order and superposed displacement time history of each feature point by using Eq. (44) conveniently. The displacement time histories of $A, B, D$ and $E$ point are the same. This is because the displacements of $A, B, D$ and $E$ point are symmetrical. The displacement time history of $C$ is different from the other four points, and the amplitude of $C$ point is maximal. This is because $C$ point is the center of the membrane, and the amplitude is the maximum spontaneously.

\section{Conclusions.}

1. This paper solved the governing equations of nonlinear free vibration of rectangular orthotropic membrane structure in large amplitude by homotopy perturbation method (HPM), and obtained the approximate analytical solution of the frequency and displacement function of the nonlinear free vibration of rectangular membrane structure with four edges simply or fixed supported.

2. The precision of Eq. (41) obtained by HPM in this paper is higher than Eq. (43) obtained by L-P perturbation method in paper [17], and (43) is only suitable for the weak nonlinear situation, namely Eq. (43) is valid only for small parameters. But Eq. (41) is not only suitable for the weak nonlinear situation, but also suitable for the strong nonlinear situation, namely Eq. (41) is valid not only for small parameters, but also for large parameters. In addition, for any value of initial displacement $w_{0}$, the maximal relative error between the homotopy perturbation solution Eq. (41) in this paper and the accurate solution Eq. (42) in paper [16] is less than $3,935 \%$.

3. From the displacement function (44), we can conveniently obtain the single-order and superposed vibration mode and displacement and time curves of the studied membrane structure. Results obtained from this paper provide some theoretical basis for the computation and control of nonlinear vibration of membrane structures, and provide some theoretical references for solving the response of membrane structures under dynamic loads. In addition, results of this paper provide some theoretical references for the dynamic design and manufacture of membrane structures.

\section{Acknowledgement.}

This work is supported by the National Natural Science Foundation of China (Project number: 51608060), the Science and Technology Research Project of Chongqing Municipal Education Commission (Project number: KJ1603602), and the Talent Fund of Chengdu University of Technology (Project number: KYGG201303).

РЕЗЮМЕ. Вивчено геометрично нелінійні коливання попередньо напруженої ортотропної мембрани 3 чотирма фіксованими краями, яка звичайно використовується в будівельних мембранних конструкціях. Нелінійні рівняння динаміки в частинних похідних отримано на базі теорії фон Кармана про великі прогини і принципу Д‘Алямбера. Застосовано метод гомотопічного збурення для розв'язування отриманих сильно нелінійних рівнянь. Отримано наближений аналітичний розвязок для частоти коливань і функції зміщень. У числовому прикладі проаналізовано частоти, форми коливань, зміщення і залежні від часу криві у кожній характерній точці. Доведено, що цей метод $є$ ефективним, 
простим і високоточним для розвязування задач про геометрично нелінійні коливання мембранних конструкцій. Ці результати створюють певну корисну базу для обчислення задач про управління коливаннями і динамічне конструювання будівельних та інших аналогічних мембранних конструкцій.

1. C.G.Wang, Y.L.Li, X.W. Du, et al, Simulation analysis of vibration characteristics of wrinkled membrane space structure, International Journal of Space Structures. 22 (4) (2007) - P. 239 - 246.

2. C.Jenkins, U.A.Korde, Membrane vibration experiments: An historical review and recent results, Journal of Sound and Vibration. 295 (3-5) (2006). - P. $602-613$.

3. Y.L.Li, M.Y.Lu, H.F.Tan, et al, A study on wrinkling characteristics and dynamic mechanical behavior of membrane, Acta Mechanica Sinica/Lixue Xuebao. 28 (1) (2012). - P. 201 - 210.

4. S.W.Kang, J.M.Lee, Free vibration analysis of composite rectangular membranes with an oblique interface, Journal of Sound and Vibration. 251 (3) (2002). - P. 505 - 517.

5. S.W.Kang, Free vibration analysis of composite rectangular membranes with a bent interface, Journal of Sound and Vibration. 272(1-2) (2004) - P. 39 - 53.

6. C.Y.Wang, C.M.Wang, Exact solutions for vibrating rectangular membranes placed in a vertical plane, International Journal of Applied Mechanics. 3 (3) (2011). - P. 625 - 631.

7. R.M.Soares, P.B.Gonalves, Nonlinear vibrations and instabilities of a stretched hyperelastic annular membrane, International Journal of Solids and Structures. 49 (3 - 4) (2006). - P. 514 - 526.

8. P.B.Goncalves, R.M.Soares, D.Pamplona, Nonlinear vibrations of a radially stretched circular hyperelastic membrane, Journal of Sound and Vibration. 327 (1-2) (2009). - P. 231 - 248.

9. Z.L.Zheng, W.J.Song, C.J.Liu, et al, Study on Dynamic Response of Rectangular Orthotropic Membranes under Impact Loading, Journal of Adhesion Science and Technology. 26(10-11) (2012). - P. $1467-1479$.

10. C.Shin, J.T.Chung, W.Kim, Dynamic characteristics of the out-of-plane vibration for an axially moving membrane, Journal of Sound and Vibration. 286 (4-5) (2005). - P. 1019 - 1031.

11. H.Zhang, J.Shan, Initial form finding and free vibration properties study of membrane, 2006 Xi'an International Conference of Architecture and Technology, Proceedings-Architecture in Harmony, Xian, China. (2006) - P. 316 - 320.

12. Y.L.Li, C.G.Wang, H.F.Tan, Research on free vibration of wrinkled membranes, Proceedings of the 5th International Conference on Nonlinear Mechanics, Shanghai, China. (2007). - P. 649 - 654.

13. J.J.Pan, M.Gu, Geometric nonlinear effect to square tensioned membrane's free vibration, Journal of Tongji University (Natural Science). 35 (11) (2007). - P. 1450 - 1454.

14. S.Y.Reutskiy, Vibration Analysis of Arbitrarily Shaped Membranes, CMES-Computer Modeling in Engineering \& Science. 51 (2) (2009). - P. 115 - 142.

15. F.Formosa, Nonlinear dynamics analysis of a membrane Stirling engine: starting and stable operation, Journal of Sound and Vibration. 326 (3-5) (2009). - P. 794 - 808.

16. Z.L.Zheng, C.J.Liu, X.T.He, et al., Free vibration analysis of rectangular orthotropic membranes in large deflection, Mathematical Problems in Engineering. 2009 (2009) Article ID 634362.

17. C.J.Liu, Z.L.Zheng, X.T.He, et al., L-P Perturbation Solution of Nonlinear FreeVibration of Prestressed Orthotropic Membrane in Large Amplitude, Mathematical Problems in Engineering. 2010 (2010) Article ID 561364.

18. J.H.He, Homotopy perturbation technique, Computer Methods in Applied Mechanics and Engineering. 178 (3) (1999). - P. $257-262$.

19. J.H.He, Homotopy perturbation method: A new nonlinear analytical technique, Applied Mathematics and Computation. 135 (1) (2003). - P. 73 - 79.

20. J.H.He, Comparison of homotopy perturbation method and homotopy analysis method, Applied Mathematics and Computation. 156 (2) (2004). - P. 527 - 539.

21. J.H.He, A coupling method of a homotopy technique and a perturbation technique for non-linear problems, International Journal of Non-Linear Mechanics. 35 (1) (2000). - P. 37 - 43.

22. J.H.He, The homotopy perturbation method for nonlinear oscillators with discontinuities, Applied Mathematics and Computation, 151 (1) (2004). - P. 287 - 292.

23. L.Cveticanin, Homotopy-perturbation method for pure nonlinear differential equation, Chaos, Solitons and Fractals. 2006. 30 (5) (2006). - P. 1221- 1230.

24. A.Yildirim, Application of the homotopy perturbation method for the Fokker-Planck equation, International Journal for Numerical Methods in Biomedical Engineering. 26 (9) (2010). - P 1144 - 1154. 
25. A.M.A.El-Sayed, A.Elsaid, I.L.El-Kalla, et al., A homotopy perturbation technique for solving partial differential equations of fractional order in finite domains, Applied Mathematics and Computation. 218 (17) (2012). - P. 8329 - 8340.

26. A.Golbabai, M.Javidi, Application of He's homotopy perturbation method for nth-order integrodifferential equations, Applied Mathematics and Computation. 190 (2) (2007). - P. 1409 - 1416.

27. B.Ozturk, S.B.Coskun, The Homotopy Perturbation Method for free vibration analysis of beam on elastic foundation, Structural Engineering and Mechanics. 37 (4) (2011). - P. 415 - 425.

28. H.Saffari, I.Mansouri, M.H. Bagheripour, et al., Elasto-plastic analysis of steel plane frames using Homotopy Perturbation Method, Journal of Constructional Steel Research. 70 (2012). - P. 350 - 357.

29. A.R.Ghotbi, A.Barari, D.D.Ganji, Solving ratio-dependent predator-prey system with constant effort harvesting using homotopy perturbation method, Mathematical Problems in Engineering. 2008 (2008) Article ID 945420.

30. K.Reck, E.V.Thomsen, O.Hansen, Solving the Helmholtz equation in conformal mapped ARROW structures using homotopy perturbation method, Optics Express, 19 (3) (2011) . - P. 1808 - 1823.

31. I.V.Andrianov, J.Awrejcewicz, V.Chernetskyy, Analysis of natural in-plane vibration of rectangular plates using homotopy perturbation approach, Mathematical Problems in Engineering. 2006 (2006) Article ID 20598.

32. G.Domairry, A.Aziz, Approximate analysis of MHD squeeze flow between two parallel disks with suction or injection by homotopy perturbation method, Mathematical Problems in Engineering. 2009 (2009) Article ID 603916.

33. F.Shakeri, M.Dehghan, Solution of delay differential equations via a homotopy perturbation method, Mathematical and Computer Modeling. 48 (3-4) (2008). - P. 486 - 498.

34. A. Yildirim, Application of He's homotopy perturbation method for solving the Cauchy reaction-diffusion problem, Computers and Mathematics with Applications. 57 (4) (2009) . - P. 612- 618.

From the Editorial Board: The article corresponds completely to submitted manuscript.

Поступила 24.06.2015

Утверждена в печать 10.10.2017 